\title{
Pengaruh Aplikasi Giberelin Pada Padi Sawah (Oryza Sativa L.)Varietas Hibrida (Hipa Jatim 2) dan Varietas Unggul Baru (Ciherang)
}

\author{
Effect of Application Giberelin on Hybrid Rice (Oryza sativa L.) Variety (Hipa Jatim 2) and \\ High Yielding Variety (Ciherang)
}

\section{Rizqi Caesar Utama dan Sugiyanta*}

Departemen Agronomi dan Hortikultura, Fakultas Pertanian, Institut Pertanian Bogor (Bogor Agricultural University), Jl. Meranti, Kampus IPB Darmaga, Bogor 16680, Indonesia Telp. \& Faks.62-251-8629353 e-mail agronipb@indo.net.id *Penulis untuk korespondensi: mr_sugiyanta@yahoo.co.id

Disetujui 18 Januari 2016/ Published online 25 Januari 2016

\begin{abstract}
This research was aimed to study about effect gibberelin to rice production Hybrid Variety (Hipa Jatim 2) and high yielding variety (Ciherang). The research was conducted in Karawang Wetan Village, Eeast Karawang, West Java. The research was arranged Split Plot by block design with 2 factors which are variety as main plot and doses of gibberelin as sub plot. The varieties which use was Hipa Jatim 2 and Ciherang. Doses of gibberelin which use was $5.6 \mathrm{~g} \mathrm{ha}^{-1}, 8 \mathrm{~g} \mathrm{ha}^{-1}, 11.2 \mathrm{~g} \mathrm{ha^{-1 } , 1 6 . 8 \mathrm { g } \mathrm { ha }}{ }^{-1}, 22.4 \mathrm{~g} \mathrm{ha}^{-1}$, and control. The observation was plant growth, yield component, and biomass plant. In this result showed that dominant pests are attacking rice plants are snails (Pomacea canaliculata) and stem borer (Schirpophaga sp.). Result from research, generally showed that Hipa Jatim 2 have plant growth higher than Ciherang variety. Ciherang variety have yield component, biomass plant, GKP and GKG higher than Hipa Jatim 2 variety. Gibberelin with doses $22.4 \mathrm{~g}$ ha-1 yield component of rice was higher than other doses. This result showed that not interaction between variety and gibberelin doses.
\end{abstract}

Keywords: Ciherang, giberellin, Hipa Jatim 2

\section{ABSTRAK}

Penelitian ini bertujuan untuk mempelajari pengaruh pemberian zat pengatur tumbuh giberelin terhadap produksi padi varietas hibrida (Hipa Jatim) dan varietas unggul baru (Ciherang). Penelitian ini dilaksanakan di Desa Karawang Wetan, Kecamatan Karawang Timur, Kabupaten Karawang, Jawa Barat pada bulan November sampai April 2014. Rancangan percobaan yang digunakan adalah adalah rancangan acak kelompok (RAK) Split Plot 2 faktor yaitu varietas sebagai petak utama dan dosis giberelin sebagai anak petak.Varietas yang digunakan yaitu Hipa Jatim 2 dan Ciherang. Dosis giberelin yang digunakan adalah $5.6 \mathrm{~g} \mathrm{ha}^{-1}, 8 \mathrm{~g} \mathrm{ha}^{-1}, 11.2 \mathrm{~g} \mathrm{ha-}^{-1}, 16.8 \mathrm{~g} \mathrm{ha}^{-1}, 22.4 \mathrm{~g} \mathrm{ha}^{-1}$, dan kontrol (tanpa aplikasi giberelin). Pengamatan yang diamati yaitu pertumbuhan tanaman, biomassa padi, komponen hasil dan hasil. Hasil penelitian menunjukkan bahwa secara umum varietas Hipa Jatim 2 menunjukkan pertumbuhan tanaman lebih tinggi dibandingkan varietas Ciherang, tetapi varietas Ciherang mempunyai komponen hasil, biomassa padi, GKP dan GKG lebih tinggi dibandingkan varietas Hipa Jatim 2. Giberelin dengan dosis $22.4 \mathrm{~g} \mathrm{ha} \mathrm{h}^{-1}$ secara umum menghasilkan komponen biomassa padi yang lebih tinggi daripada pemberian dosis lainnya. Hasil penelitian ini juga menunjukkan bahwa tidak ada interaksi antara verietas dan perlakuan beberapa dosis giberelin.

Kata kunci : Ciherang, giberellin, Hipa Jatim 2 


\section{PENDAHULUAN}

Padi merupakan makanan pokok sebagian besar penduduk Indonesia. Konsumsi beras rata-rata di Indonesia pada tahun 2013 adalah $78.816 \mathrm{~kg}$ per kapita per tahun. Besarnya konsumsi beras dalam negeri tidak sebanding dengan produktivitas padi yang melandai. Produktivitas padi per hektar meningkat sebesar $0.31 \%$ dari tahun 2012 sebesar 51.36 kuintal per hektar menjadi 51.52 kuintal per hektar pada tahun 2013 (BPS, 2013). Upaya produktivitas padi dapat ditingkatkan dengan menggunakan varietas unggul dan pemberian zat pengatur tumbuh (ZPT).

Zat pengatur tumbuh adalah salah satu bahan sintetis atau hormon tumbuhan yang mempengaruhi proses fisiologi. Pengaturan pertumbuhan ini dilakukan dengan cara pembentukan hormon-hormon yang sama, mempengaruhi sintesis hormon, perusakan translokasi, atau dengan perubahan tempat pembentukan hormon. Menurut Wattimena (1988) hormon tanaman adalah senyawa organik bukan nutrisi yang aktif dalam jumlah kecil yang disintesakan pada bagian lain tanaman dan pada umumnya diangkut ke bagian lain tanaman dimana zat tersebut menimbulkan tanggapan secara biokimia, fisiologis dan morfologis. Wattimena juga menambahkan bahwa jenis ZPT yang sering digunakan antara lain giberelin, kenetin dan etepon. Respon tanaman yang sering muncul akibat aktivitas giberelin adalah peningkatan pemanjangan sel terutama terjadi pada bagian batang (Salisbury, 1957). Penelitian Hess (1975) mengemukakan efek lain dari giberelin antara lain memacu kecambah, meningkatkan pembelahan sel, menghambat kerontokan daun dan buah serta menstimulir pembungaan tanaman hari panjang.

Salah satu zat pengatur tumbuh yang dapat mengatur pertumbuhan dan bentuk tanaman pada seluruh tahap dan fase pertumbuhan tanaman yaitu giberelin. Giberelin termasuk zat pengatur tumbuh yang berguna bagi tanaman, dalam konsentrasi rendah dapat merangsang pembelahan dan pemanjangan sel (Lingga, 1998). Efek giberelin tidak hanya mendorong pemanjangan batang, tetapi juga terlibat dalam proses regulasi perkembangan tumbuhan seperti halnya auksin. Giberelin disintesis pada ujung batang dan akar sehingga menghasilkan pengaruh yang cukup luas. Salah satu efek utamanya adalah mendorong pemanjangan batang dan daun.

Giberelin berperan meningkatkan tinggi padi tipe padi kerdil. Percobaan Mukarami (1995) menunjukkan penambahan giberelin $0.1-10 \mathrm{ppm}$ pada larutan sukrosa menyebabkan pemanjangan pelepah daun sebesar 5-6 $\mathrm{mm}$. Efek lainnya antara lain menstimulasi pertumbuhan pada internoda yang dipotong dan menginduksi sintesis amilase yang berperan untuk memecah endosperm sehingga perkecambahan meningkat. Pengaruh ZPT giberelin pada tanaman padi sawah belum banyak diketahui, untuk itu perlu diteliti pengaruh giberelin terhadap pertumbuhan dan hasil padi varietas hibrida dan inbrida. Penggunaan VUB terus dikembangkan untuk meningkatkan hasil tanaman padi sawah, namun saat ini potensi genetik daya hasil VUB telah mendekati titik maksimum sehingga tidak dapat lagi ditingkatkan. Beberapa pemulia tanaman padi mulai mengembangkan varietas hibrida yang diharapkan dapat meningkatkan hasil padi sawah. Menurut Imran dan Suriany (2009) padi hibrida memiliki pertumbuhan yang lebih baik dari pada padi varietas unggul baru dan menghasilkan gabah kering panen per hektar 39\% lebih tinggi dari pada varietas unggul baru.

\section{BAHAN DAN METODE}

Bahan-bahan yang digunakan dalam penelitian ini adalah benih padi varietas Ciherang dan Hipa Jatim 2, Giberelin, dan pupuk NPK (30-6-8). Alat yang digunakan adalah alat budidaya tanaman, oven, timbangan, meteran dan bagan warna daun (BWD).

Penelitian ini dilaksanakan di Desa Karawang Wetan, Kecamatan Karawang Timur, Kabupaten Karawang, Jawa Barat. Penelitian dilaksanakan pada bulan November 2013 Maret 2014. Rancangan percobaan yang digunakan adalah Rancangan Acak Kelompok (RAK) Split Plot dengan 2 faktor yaitu: varietas sebagai petak utama, dan pemberian dosis giberelin sebagai anak petak. Faktor pertama adalah varietas yang terdiri dari Varietas Ciherang dan Hipa Jatim 2. Faktor kedua adalah pemberian dosis giberelin yaitu dosis $5.6 \mathrm{~g} \mathrm{ha}^{-1}$, 1) $8 \mathrm{~g} \mathrm{ha}^{-1}, 2$ ) $11.2 \mathrm{~g} \mathrm{ha}^{-1}$, 3) $16.8 \mathrm{~g} \mathrm{ha}^{-1}$, 4) $22.4 \mathrm{~g} \mathrm{ha}^{-1}$, 5) dan kontrol 6). Aplikasi giberelin dilakukan pada saat tanaman berumur HST, penyemprotan giberelin dilakukan pada sore hari untuk menghindari penguapan. Percobaan terdiri atas 6 perlakuan pemberian dosis, 2 varietas, dan 4 ulangan sehingga diperoleh 48 satuan percobaan dengan luasan satuan percobaan $25 \mathrm{~m}^{2}$.

Peubah yang diamati pada penelitian ini yaitu pertumbuhan tanaman (tinggi tanaman, jumlah anakan, skor warna daun, dan biomassa tanaman), komponen hasil (jumlah anakan produktif, bobot 1000 butir, jumlah gabah per malai dan persentase gabah isi) dan hasil (bobot 
gabah per tanaman dan gabah kering giling/GKG). Data hasil pengamatan dianalisis dengan menggunakan uji $\mathrm{F}$ (analisis ragam), dan apabila hasil uji $\mathrm{F}$ nyata, maka dilanjutkan dengan uji jarak berganda Duncan (Duncan Multiple Range Test/DMRT) pada taraf 5\%.

\section{HASIL DAN PEMBAHASAN}

\section{Pertumbuhan Tanaman}

Tinggi tanaman. Secara umum tidak terdapat interaksi antara perlakuan varietas dan dosis giberelin terhadap peubah pertumbuhan tanaman, komponen hasil dan hasil tanaman padi, tetapi untuk masing-masing perlakuan (varietas dan dosis giberelin) menunjukkan pengaruh nyata. Tabel 1 menunjukkan bahwa tinggi tanaman padi varietas Hipa Jatim 2 lebih tinggi dibandingkan varietas Ciherang pada saat tanaman berumur $7-8$ minggu setelah tanam (MST). Hasil analisis statistik menunjukkan bahwa saat padi berumur 8 MST, perlakuan dosis $22.4 \mathrm{~g} \mathrm{ha}^{-1}$ menghasilkan tinggi tanaman yang nyata lebih tinggi dibandingkan kontrol. Berdasarkan deskripsi varietas, tinggi tanaman varietas Hipa Jatim 2 lebih tinggi dari pada varietas Ciherang (Balai Besar Penelitian Tanaman Padi, 2012). Hal ini terkait dengan varietas Hipa Jatim 2 yang tergolong varietas hibrida yang dirakit dengan tinggi tanaman yang lebih tinggi dibandingkan varietas Ciherang. Tinggi tanaman yang pendek merupakan penciri padi varietas unggul baru (VUB) yang berkaitan dengan ketahanan terhadap rebah batang. Respon tanaman terhadap giberelin yang sering muncul yaitu terjadi pemanjangan batang. Pada beberapa tanaman, giberelin menginduksi pembungaan dan membuat tanaman kerdil memiliki pertumbuhan yang normal, memacu pematahan dormansi biji dan efek buah partenokarpik (Salisbury dan Ross, 1995).

Secara umum, tinggi tanaman meningkat sesuai dengan peningkatan dosis giberelin (Tabel 1). Selain itu, perlakuan berbagai dosis giberelin memberikan hasil yang lebih tinggi jika dibandingkan dengan kontrol. Aplikasi $22.4 \mathrm{~g} \mathrm{ha}^{-1}$ giberelin menghasilkan tinggi tanaman yang lebih tinggi bila dibandingkan perlakuan kontrol saat tanaman berumur 8 MST. Abidin (1985) menjelaskan bahwa giberelin akan mendorong terjadinya pemanjangan sel karena adanya hidrolisa pati yang dihasilkan sehingga mendukung terbentuknya $\alpha$ amylase. Sebagai akibat dari proses tersebut maka konsentrasi gula meningkat yang mengakibatkan tekanan osmotik di dalam sel menjadi naik, sehingga kecenderungan sel tersebut berkembang. Menurut Wattimena (1990) respon utama tanaman terhadap ZPT giberelin adalah perpanjangan ruas tanaman yang disebabkan oleh bertambahnya ukuran dan jumlah sel pada ruas-ruas tersebut. Penelitian Dunand (1999), menunjukkan bahwa dengan 2-5 $\mathrm{g} \mathrm{ha}^{-1}$ giberelin, varietas-varietas padi pendek seperti Bengal, Jefferson, dan Lafitte mengalami peningkatan vigor benih sebesar 25$50 \%$ dan mengalami pertambahan tinggi pada saat pembibitan sebesar 3-5 inci.

Tabel 1. Pengaruh varietas dan dosis giberelin terhadap tinggi tanaman padi

\begin{tabular}{lcc}
\hline \multirow{2}{*}{\multicolumn{1}{c}{ Perlakuan }} & \multicolumn{2}{c}{ Tinggi tanaman $(\mathrm{cm})$} \\
\cline { 2 - 3 } & $7 \mathrm{MST}$ & $8 \mathrm{MST}$ \\
\hline Dosis Giberelin $\left(\mathrm{g} \mathrm{ha}^{-1}\right)$ & & \\
Kontrol & $89.86 \mathrm{a}$ & $98.21 \mathrm{~b}$ \\
5.6 & $88.93 \mathrm{a}$ & $102.34 \mathrm{ab}$ \\
8 & $88.07 \mathrm{a}$ & $100.15 \mathrm{ab}$ \\
11.2 & $90.05 \mathrm{a}$ & $103.32 \mathrm{ab}$ \\
16.8 & $90.40 \mathrm{a}$ & $103.28 \mathrm{ab}$ \\
22.4 & $92.02 \mathrm{a}$ & $105.40 \mathrm{a}$ \\
\hline
\end{tabular}

Keterangan: Angka-angka pada kolom yang sama diikuti oleh huruf yang sama tidak berbeda nyata pada taraf uji 5\% (uji selang berganda Duncan)

\section{Jumlah Anakan}

Jumlah anakan padi varietas Hipa Jatim 2 nyata lebih banyak dibandingkan padi varietas Ciherang pada 7 dan 8 MST. Hal ini dikarenakan varietas Hipa Jatim 2 dirancang dengan jumlah anakan yang lebih banyak jika dibandingkan dengan varietas Ciherang (Balai Besar Penelitian Padi, 2014).

Tabel 2. Pengaruh varietas padi dan dosis giberelin terhadap jumlah anakan padi

\begin{tabular}{lcc}
\hline \multirow{2}{*}{ Perlakuan } & \multicolumn{2}{c}{ Jumlah anakan padi $(\mathrm{cm})$} \\
\cline { 2 - 3 } & 7 MST & 8 MST \\
\hline Varietas & & \\
Hipa Jatim 2 & $23.41 \mathrm{a}$ & $20.03 \mathrm{a}$ \\
Ciherang & $19.94 \mathrm{~b}$ & $17.18 \mathrm{~b}$ \\
Dosis Giberelin $\left(\mathrm{g} \mathrm{ha}^{-1}\right)$ & & \\
Kontrol & $19.26 \mathrm{a}$ & $17.52 \mathrm{a}$ \\
5.6 & $23.36 \mathrm{a}$ & $20.49 \mathrm{a}$ \\
8 & $23.39 \mathrm{a}$ & $19.82 \mathrm{a}$ \\
11.2 & $21.57 \mathrm{a}$ & $19.48 \mathrm{a}$ \\
16.8 & $21.36 \mathrm{a}$ & $17.59 \mathrm{a}$ \\
22.4 & $21.10 \mathrm{a}$ & $18.35 \mathrm{a}$ \\
\hline
\end{tabular}

Angka-angka pada kolom yang sama diikuti oleh huruf yang sama tidak berbeda nyata pada taraf uji 5\% (uji selang berganda Duncan)

Perlakuan dosis giberelin menghasilkan jumlah anakan padi yang tidak berbeda nyata pada 7 MST maupun 8 MST. Hal ini diduga karena kadar giberelin endogenous pada tanaman sudah tinggi, sehingga aplikasi 
giberelin eksogenous tidak perpengaruh nyata (Lestari, 2006). Pernyataan tersebut didukung oleh Murakami (1995) yang menyatakan bahwa setelah transplanting umumnya kadar giberelin endogenous meningkat hingga mencapai puncaknya pada masa anakan maksimum.

Tabel 3. Pengaruh varietas padi dan dosis giberelin terhadap skor warna daun

\begin{tabular}{ccc}
\hline \multirow{2}{*}{ Perlakuan } & \multicolumn{2}{c}{ Skor warna daun } \\
\cline { 2 - 3 } & 7 MST & 8 MST \\
\hline
\end{tabular}

\begin{tabular}{lll}
\hline Varietas & & \\
$\begin{array}{l}\text { Hipa Jatim 2 } \\
\text { Ciherang }\end{array}$ & & \\
Dosis Giberelin $\left(\mathrm{g} \mathrm{ha}^{-1}\right)$ & & \\
Kontrol & $3.1 \mathrm{~b}$ & $3.2 \mathrm{a}$ \\
5.6 & $3.1 \mathrm{ab}$ & $3.3 \mathrm{a}$ \\
8 & $3.2 \mathrm{ab}$ & $3.3 \mathrm{a}$ \\
11.2 & $3.2 \mathrm{ab}$ & $3.2 \mathrm{a}$ \\
16.8 & $3.2 \mathrm{ab}$ & $3.3 \mathrm{a}$ \\
22.4 & $3.3 \mathrm{a}$ & $3.3 \mathrm{a}$ \\
\hline
\end{tabular}

Angka-angka pada kolom yang sama diikuti oleh huruf yang sama tidak berbeda nyata pada taraf uji 5\% (uji selang berganda Duncan)

Skor warna daun. Hasil pengamatan menunjukkan bahwa skor warna daun pada varietas Ciherang lebih tinggi dibandingkan varietas Hipa Jatim 2 saat tanaman berumur $7-8$ MST (Tabel 3). Saat berumur 7 MST, aplikasi $22.4 \mathrm{~g} \mathrm{ha}^{-1}$ giberelin nyata menghasilkan skor warna daun yang lebih tinggi dibandingkan dengan perlakuan kontrol. Hal ini diduga aplikasi giberelin dapat menghambat senesen. Taiz dan Zeiger (1998) menyatakan dengan dihambatnya senesen daun mengakibatkan fotosintesis berlangsung lama, sehingga asimilat yang terbentuk akan lebih banyak dan dapat mempengaruhi pertumbuhan generatif. Aplikasi giberelin pada 8 MST tidak berpengaruh nyata terhadap kehijauan daun. Hal ini sejalan dengan penelitian Permanasari dan Sulistyaningsih (2013), bahwa kehijauan daun yang diamati pada umur 8 MST tidak dipengaruhi oleh perlakuan konsentrasi giberelin.

Biomassa tanaman. Biomassa padi yang diamati dalam penelitian ini yaitu panjang tajuk, bobot basah tajuk, bobot kering tajuk, panjang akar, bobot basah akar, bobot kering akar, dan volume akar. Hasil penelitian menunjukkan bahwa panjang tajuk pada varietas Hipa Jatim 2 lebih tinggi dibandingkan dengan padi varietas Ciherang (Tabel 4). Hal ini berhubungan dengan tinggi tanaman pada dua varietas tersebut dimana varietas Hipa Jatim 2 lebih tinggi dari varietas Ciherang (Tabel 2). Berbeda dengan panjang tajuk, bobot basah tajuk dan bobot kering tajuk pada varietas Ciherang lebih besar dibandingkan dengan varietas Hipa Jatim 2 (Tabel 4).

Tabel 4. Pengaruh varietas padi dan dosis giberelin terhadap panjang tajuk, bobot basah dan kering tajuk

\begin{tabular}{|c|c|c|c|}
\hline Perlakuan & Panjang tajuk $(\mathrm{cm})$ & Bobot basah tajuk (g) & Bobot kering tajuk (g) \\
\hline \multicolumn{4}{|l|}{ Varietas } \\
\hline Hipa Jatim 2 & $106.14 \mathrm{a}$ & $190.42 \mathrm{~b}$ & $50.438 \mathrm{~b}$ \\
\hline \multirow{2}{*}{\multicolumn{4}{|c|}{ Dosis Giberelin $\left(\mathrm{g} \mathrm{ha}^{-1}\right)$}} \\
\hline & & & \\
\hline Kontrol & $96.91 \mathrm{ab}$ & $210.05 a$ & $60.81 \mathrm{a}$ \\
\hline 5.6 & $100.10 \mathrm{ab}$ & $196.81 \mathrm{a}$ & $48.25 \mathrm{a}$ \\
\hline 8 & $100.62 \mathrm{ab}$ & $186.19 a$ & $54.31 \mathrm{a}$ \\
\hline 11.2 & $92.31 \mathrm{~b}$ & $226.81 \mathrm{a}$ & $60.63 a$ \\
\hline 16.8 & $104.49 \mathrm{a}$ & $220.69 a$ & $75.75 a$ \\
\hline 22.4 & $103.42 \mathrm{ab}$ & $227.31 \mathrm{a}$ & $77.81 \mathrm{a}$ \\
\hline
\end{tabular}

Angka-angka pada kolom yang sama diikuti oleh huruf yang sama tidak berbeda nyata pada taraf uji 5\% (uji selang berganda Duncan)

Perlakuan dosis pada panjang tajuk menunjukkan bahwa perlakuan dosis giberelin tidak berbeda nyata jika dibandingkan dengan kontrol. Perlakuan giberelin menunjukkan bahwa bobot basah dan kering tajuk tanaman menunjukkan hasil yang tidak berbeda nyata. Hal ini sejalan dengan pengamatan sebelumnya yang menunjukkan bahwa giberelin tidak berpengaruh meningkatkan tinggi tanaman (Tabel 1) dan jumlah anakan (Tabel 2). Tabel 4 menunjukkan perlakuan dosis giberelin $22.4 \mathrm{~g} \mathrm{ha}^{-1}$ cenderung menghasilkan bobot basah dan kering tajuk tertinggi dibandingkan perlakuan dosis giberelin lainnya .

Pelakuan varietas (Tabel 5) menunjukkan bahwa panjang dan volume akar pada varietas Ciherang nyata lebih tinggi bila dibandingkan dengan varietas Hipa Jatim 2. Bobot basah dan kering akar pada perlakuan varietas tidak menunjukkan hasil yang berbeda nyata. 
Tabel 5. Pengaruh varietas padi dan dosis giberelin terhadap biomassa padi

\begin{tabular}{|c|c|c|c|c|}
\hline Perlakuan & $\begin{array}{l}\text { Panjang akar } \\
(\mathrm{cm})\end{array}$ & $\begin{array}{l}\text { Volume akar } \\
(\mathrm{ml})\end{array}$ & $\begin{array}{c}\text { Bobot basah akar } \\
(\mathrm{g})\end{array}$ & $\begin{array}{c}\text { Bobot kering akar } \\
(\mathrm{g})\end{array}$ \\
\hline \multicolumn{5}{|l|}{ Varietas } \\
\hline Hipa Jatim 2 & $22.76 b$ & $50.31 \mathrm{~b}$ & $71.94 a$ & $27.56 \mathrm{a}$ \\
\hline Ciherang & $32.39 \mathrm{a}$ & $71.67 \mathrm{a}$ & $74.75 \mathrm{a}$ & $27.23 \mathrm{a}$ \\
\hline \multicolumn{5}{|l|}{ Dosis Giberelin $\left(\mathrm{g} \mathrm{ha}^{-1}\right)$} \\
\hline Kontrol & $24.94 \mathrm{a}$ & $50.00 \mathrm{~b}$ & $64.31 \mathrm{a}$ & $20.01 b$ \\
\hline 5.6 & $27.78 \mathrm{a}$ & $53.75 \mathrm{ab}$ & $75.62 \mathrm{a}$ & $21.62 b$ \\
\hline 8 & $26.85 a$ & $59.37 \mathrm{ab}$ & $72.69 \mathrm{a}$ & $20.12 b$ \\
\hline 11.2 & $34.80 \mathrm{a}$ & $68.75 \mathrm{a}$ & $77.81 \mathrm{a}$ & $32.19 a$ \\
\hline 16.8 & $25.68 \mathrm{a}$ & $65.62 \mathrm{ab}$ & $76.50 \mathrm{a}$ & $36.31 \mathrm{a}$ \\
\hline 22.4 & $25.41 \mathrm{a}$ & $68.44 \mathrm{a}$ & $73.12 \mathrm{a}$ & $33.85 \mathrm{a}$ \\
\hline
\end{tabular}

Angka-angka pada kolom yang sama diikuti oleh huruf yang sama tidak berbeda nyata pada taraf uji 5\% (uji selang berganda Duncan)

Perlakuan dosis giberelin juga tidak berpengaruh nyata meningkatkan panjang akar dan bobot basah akar. Namun pada volume akar dan bobot kering akar menunjukkan bahwa perlakuan dosis giberelin menghasilkan hasil yang berbeda nyata. Aplikasi 11.2 dan 22.4 $\mathrm{g} \mathrm{ha}^{-1}$ giberelin nyata menghasilkan volume akar yang lebih tinggi dibandingkan kontrol (Tabel 5). Hal ini sependapat dengan penelitian Supriyadi (2006) yang menunjukkan bahwa semakin tinggi konsentrasi giberelin maka volume akar semakin besar. Pemberian giberelin diduga berpengaruh meningkatkan pembelahan sel yang dapat memicu perbanyakan cabang sehingga volume akar meningkat. Peningkatan volume akar tersebut diharapkan dapat meningkatkan daya serap akar terhadap hara nutrisi yang berbeda pada tanah.

Perlakuan bobot kering akar dengan pemberian dosis giberelin sebesar $11.2 \mathrm{~g} \mathrm{ha}^{-1}$, 16.8 $\mathrm{g} \mathrm{ha}^{-1}, 22.4 \mathrm{~g} \mathrm{ha}^{-1}$ nyata memberikan hasil yang lebih tinggi dibandingkan kontrol. Hal ini diduga berkaitan dengan volume akar (Tabel 5) yang semakin tinggi dengan meningkatkan dosis giberelin yang diberikan.

\section{Komponen Hasil dan Hasil Tanaman Padi Sawah}

Komponen hasil. Varietas Ciherang nyata menghasilkan jumlah anakan produktif dan panjang malai lebih tinggi dibandingkan dengan varietas Hipa Jatim2 (Tabel 6). Jumlah gabah per malai pada varietas Hipa Jatim 2 lebih tinggi dibandikan varietas Ciherang. Hal ini sesuai dengan deskripsi varietas yng dikeluarkan oleh Balai Besar Penelitian Padi (2014) bahwa jumlah gabah permalai yang dihasilkan oleh varietas Hipa Jatim 2 memang lebih banyak jika dibandingkan dengan varietas Ciherang.

Tabel 6. Pengaruh varietas padi dan dosis giberelin terhadap jumlah anakan produktif, panjang malai, dan jumlah gabah per malai

\begin{tabular}{lccc}
\hline \multicolumn{1}{c}{ Perlakuan } & Jumlah anakan produktif & Panjang malai $(\mathrm{cm})$ & Jumlah gabah per malai \\
\hline Varietas & & & \\
Hipa Jatim 2 & $12.58 \mathrm{~b}$ & $23.89 \mathrm{~b}$ & $200.72 \mathrm{a}$ \\
Ciherang & $15.87 \mathrm{a}$ & $24.59 \mathrm{a}$ & $130.03 \mathrm{~b}$ \\
$\begin{array}{l}\text { Dosis Giberelin (g ha-1) } \\
\text { Kontrol }\end{array}$ & $12.70 \mathrm{c}$ & $24.28 \mathrm{ab}$ & \\
5.6 & $14.45 \mathrm{abc}$ & $24.76 \mathrm{a}$ & $149.77 \mathrm{~b}$ \\
8 & $15.00 \mathrm{ab}$ & $24.16 \mathrm{ab}$ & $169.21 \mathrm{a}$ \\
11.2 & $16.17 \mathrm{a}$ & $23.36 \mathrm{~b}$ & $169.11 \mathrm{a}$ \\
16.8 & $13.46 \mathrm{bc}$ & $24.48 \mathrm{ab}$ & $168.86 \mathrm{a}$ \\
22.4 & $13.56 \mathrm{bc}$ & $24.42 \mathrm{ab}$ & $167.35 \mathrm{a}$ \\
\hline
\end{tabular}

Angka-angka pada kolom yang sama diikuti oleh huruf yang sama tidak berbeda nyata pada taraf uji 5\% (uji selang berganda Duncan)

Varietas Ciherang nyata menghasilkan gabah isi yang lebih tinggi bila dibandingkan varietas Hipa Jatim 2 (Tabel 7). Hal ini diduga karena pengisian bulir pada Hipa Jatim 2 tidak sebaik pengisian bulir pada Ciherang karena pada varietas Hipa Jatim 2 sink lebih besar jika dibandingkan source, sehingga jumlah butir padi yang dihasilkan lebih banyak (Tabel 7), namun pengisian bulir tidak merata dan menyebabkan hampir $20 \%$ bulir hampa, namun pada peubah persentase bobot 1000 butir perlakuan varietas tidak menunjukkan perbedaan yang nyata. 
Tabel 7. Pengaruh varietas padi dan dosis giberelin terhadap bobot 1000 butir dan gabah isi

\begin{tabular}{lcc}
\hline \multicolumn{1}{c}{ Perlakuan } & $\begin{array}{c}\text { Persentase } \\
\text { gabah isi }(\%)\end{array}$ & $\begin{array}{c}\text { Bobot } 1000 \\
\text { butir }(\mathrm{g})\end{array}$ \\
\hline Varietas & & \\
Hipa Jatim 2 & $81.95 \mathrm{~b}$ & $25.58 \mathrm{a}$ \\
Ciherang & $94.20 \mathrm{a}$ & $25.85 \mathrm{a}$ \\
Dosis Giberelin $\left(\mathrm{g} \mathrm{ha}^{-1}\right)$ & & \\
Kontrol & $88.12 \mathrm{a}$ & $24.87 \mathrm{~b}$ \\
5.6 & $88.12 \mathrm{a}$ & $25.37 \mathrm{~b}$ \\
8 & $87.25 \mathrm{a}$ & $26.00 \mathrm{ab}$ \\
11.2 & $88.00 \mathrm{a}$ & $25.50 \mathrm{ab}$ \\
16.8 & $87.10 \mathrm{a}$ & $25.75 \mathrm{ab}$ \\
22.4 & $89.80 \mathrm{a}$ & $26.75 \mathrm{a}$ \\
\hline
\end{tabular}

Angka-angka pada kolom yang sama diikuti oleh huruf yang sama tidak berbeda nyata pada taraf uji 5\% (uji selang berganda Duncan)

Aplikasi giberelin pada tanaman padi sawah tidak nyata meningkatkan persentase gabah isi, namun nyata meningkatkan bobot 1000 butir dengan aplikasi dosis $22.4 \mathrm{~g} \mathrm{ha}^{-1}$ (Tabel 7). Peningkatan kandungan giberelin yang sesuai dapat menyebabkan jumlah klorofil di dalam tanaman menjadi bertambah yang pada akhirnya proses fotosintesis pada tanaman meningkat. Hasil fotosintesis (fotosintat) tersebut selanjutnya oleh tanaman, yang pada akhirnya dapat meningkatkan hasil padi, seperti halnya bertambahnya bobot 1000 butir gabah (Toharudin dan Sutomo, 2013).

Tabel 8. Pengaruh varietas padi dan dosis giberelin terhadap hasil tanaman padi

\begin{tabular}{lcc}
\hline \multicolumn{1}{c}{ Perlakuan } & GKP $\left(\right.$ ton ha $\left.{ }^{-1}\right)$ & GKG $($ ton ha \\
\hline Varietas & & \\
Hip Jatim 2 & $4.82 \mathrm{~b}$ & $4.07 \mathrm{~b}$ \\
Ciherang & $6.79 \mathrm{a}$ & $5.74 \mathrm{a}$ \\
Dosis $\left(\mathrm{g} \mathrm{ha}^{-1}\right)$ & & \\
Kontrol & $5.17 \mathrm{a}$ & $4.37 \mathrm{a}$ \\
5.6 & $5.96 \mathrm{a}$ & $5.06 \mathrm{a}$ \\
8 & $6.06 \mathrm{a}$ & $5.11 \mathrm{a}$ \\
11.2 & $5.74 \mathrm{a}$ & $4.80 \mathrm{a}$ \\
16.8 & $6.11 \mathrm{a}$ & $5.15 \mathrm{a}$ \\
22.4 & $5.81 \mathrm{a}$ & $4.95 \mathrm{a}$ \\
\hline
\end{tabular}

Angka-angka pada kolom yang sama diikuti oleh huruf yang sama tidak berbeda nyata pada taraf uji 5\% (uji selang berganda Duncan)

Hasil tanaman padi sawah. Varietas Ciherang menghasilkan gabah kering panen (GKP) dan gabah kering giling (GKG) lebih tinggi dibandingkan varietas Hipa Jatim2. Hal ini diduga karena varietas Ciherang sering digunakan para petani di daerah tersebut dan sangat cocok pertumbuhannya. Pemberian dosis giberelin 522.4 $\mathrm{g} \mathrm{ha}^{-1}$ menghasilkan GKP dan GKG yang tidak berbeda dengan perlakuan kontrol. Hal ini berbeda dengan penelitian Dunand et al (1992) menyatakan perlakuan konsentrasi GA3 6.26 ppm dapat meningkatkan hasil gabah hingga $162 \%$ (Tabel 8).

\section{KESIMPULAN}

Pemberian giberelin secara umum dapat meningkatkan pertumbuhan dan komponen hasil tanaman, namun tidak terlihat meningkatkan hasil tanaman padi. Varietas Hipa Jatim 2 menghasilkan pertumbuhan yang lebih baik dibandingkan varietas Ciherang. Varietas Ciherang secara umum menghasilkan komponen hasil dan hasil yang lebih lebih tinggi dibandingkan dengan varietas Hipa Jatim 2.

\section{DAFTAR PUSTAKA}

Abidin, Z. 1985. Dasar-dasar Pengetahuan Tentang ZPT. Bandung (ID): Angkasa.

BPS [Badan Pusat Statistik]. 2013. Produksi padi di Indonesia [Internet]. [diunduh 2014 Apr 20]. Tersedia pada: http://www.bps.go.id/tnmn_pgn.php?kat= 3\&id_subyek $=53 \&$ notab $=0$.

BPS [Badan Pusat Statistik]. 2013. Rata-rata Konsumsi per Kapita [Internet]. [diunduh 2015 Feb 17]. Tersedia pada: http://www.bps.go.id/webbeta/frontend/li nkTabel Statis/ view/id/950.

Dunand, R.T. 1999. Improvement of Rice Production with Plant Growth Regulators. Lousiana State University, Rice Research Center.

Eiichi, T. 2005. Regulation of root growth by plant hormones role for auxin and gibberellin. Critical Reviews in Plant Sciences 24 (4): 249-265.

Hayashi, T. 1961. The effect of gibberellin treatment on the photosynthetic activity of plants. Sixth International Conference. Plant Growth Regulator. 579-589.

Hess, D. 1975. Plant Physiology. America (US): Spinger-Verlag New York Inc.

Permanasari, Sulistyaningsih, E. 2013. Kajian fisiologi perbedaan kadar lengas tanah dan konsentrasi giberelin pada kedelai (Glycine max L.). J. Agroteknologi 4(1): 31-39. 
Kusumo, S. 1990. Zat Pengatur Tumbuh Tanaman. Bogor (ID): Yasaguna.

Lestari, F. 2006. Pengaruh zat pengatur tumbuh giberelin terhadap pertumbuhan dan hasil serta mutu gabah dan beras [skripsi]. Bogor (ID): Institut Pertanian Bogor.

Ludford, P. M. 1995. Postharvest Hormone Change In Vegetative and Fruits. In P J Davies, (ed). Plant Hormones. Netherlands: Kluwer Academic Publisher.

Moody, K. 1986. Role of plant growth regulators in tropical rice cultication. FFTC Book 34: $158-147$.

Murakami, Y. 1995. Gibberellins. In: Matsuo T, Kumazawa K, Ishii R, Ishuhara K, Hirata $\mathrm{H}$, editors. Science of Rice Plant Volume II : Plant Physiology. Tokyo: Food and Agriculture Policy Center. p 182-189.

Moore, T.C. 1979. Biochemistry and Physiology of Plant Hormones. New York: SpringerVerlag New York Inc.

Salisbury, F.B. 1957. Plant Life. New York (US): Scientific American Inc.

Salisbury, F.B, Cleon, W Ross. 1995. Fisiologi Tumbuhan Jilid Tiga. Bandung (ID): Institut Teknologi Bandung. 51-62
Susilowati, Y.E, Andjarwani. 2008. Pengaruh kadar giberelin dan kinetin terhadap pertumbuhan dan hasil beberapa varietas storberi. J. Penelitian Inovasi 29 (1): 110-127.

Supriyadi. 2006. Pengaruh konsentrasi dan waktu aplikasi giberelin gibgro $10 \mathrm{sp}$ terhadap pertumbuhan, hasil dan mutu fisik hasil padi sawah (Oryza sativa L.) [skripsi]. Bogor (ID): Institut Pertanian Bogor.

Taiz, L. E. Zeiger. 1998. Plant Physiology. Massachusetts: Sineaur. Associate. lnc. Publisher.

Toharudin, M, Sutomo, MH. 2013. Pengaruh pemberian pupuk nitrogen dan zat pengatur tumbuh giberelin terhadap serapan $\mathrm{N}$, pertumbuhan dan hasil tanaman padi (Oryza sativa L.). $J$. Agroswagati 2(2):11-21.

Wattimena, G.A. 1988. Zat Pengatur Tumbuh. Bogor (ID): Pusat Antar Universitas IPB.

Yan, W, Dilday, R., Bourland, F. 2004. Effects Of Gibberellic Acid On Rice Germination And Seeding Emergence In Stress Conditions. Arkansas Agricultural Experiment Station Research Series 517. 309-316. 